\title{
Can Economic Assistance Shape Combatant Support in Wartime? Experimental Evidence from Afghanistan
}

\author{
JASON LYALL Dartmouth College \\ YANG-YANG ZHOU University of British Columbia \\ KOSUKE IMAI Harvard University
}

\begin{abstract}
$G$ overnments, militaries, and aid organizations all rely on economic interventions to shape civilian attitudes toward combatants during wartime. We have, however, little individual-level evidence that these "hearts and minds" programs actually influence combatant support. We address this problem by conducting a factorial randomized control trial of two common interventions-vocational training and cash transfers-on combatant support among 2,597 at-risk youth in Kandahar, Afghanistan. We find that training only improved economic livelihoods modestly and had little effect on combatant support. Cash failed to lift incomes, producing a boom-and-bust dynamic in which pro-government sentiment initially spiked and then quickly reversed itself, leaving a residue of increased Taliban support. Conditional on training, cash failed to improve beneficiaries' livelihoods but did increase support for the Afghan government for at least eight months after the intervention. These findings suggest that aid affects attitudes by providing information about government resolve and competence rather than by improving economic livelihoods.
\end{abstract}

Jason Lyall (D), James Wright Associate Professor in Transnational Studies, Department of Government, Dartmouth College, jason. lyall@dartmouth.edu.

Yang-Yang Zhou (iD, Assistant Professor, Department of Political Science, University of British Columbia, yangyang.zhou@ubc.ca.

Kosuke Imai (D), Professor, Department of Government and Department of Statistics, Harvard University, imai@harvard.edu.

We thank Mercy Corps, and especially Ninette Adhikari, Naquib Ahmad, Keith Ives, Max Izenberg, Jon Kurtz, Beza Tesfaye, Muhammed Ashraf Wahidi, and Rebecca Wolfe for the opportunity to evaluate the INVEST-Kandahar initiative. We also thank colleagues at MRA Associates, Roshan Telecom Afghanistan, and Sayara International, including Abdul Rahim Israr, Haroon Rasheed, and Nama Vanier, and especially our 30 enumerators, for excellent work under difficult circumstances. We are especially grateful for Prakhar Sharma for exemplary project management. We also wish to acknowledge the tragic death of Rahmatullah Nasiry, who oversaw our project as Roshan's Financial Manager, and who was killed in the horrific suicide bombing in Kabul on May 31, 2017. Lars-Erik Cederman, James Fearon, Benjamin Fifield, Anita Gohdes, David Laitin, Rich Nielsen, Renard Sexton, Francesco Trebbi, Nils Weidmann, and Jeremy Weinstein, along with audiences at the Vancouver School of Economics, the University of Zurich, ETH-Zurich, University of Konstanz, Harvard University, New York University-Abu Dhabi, NYU-CESS, Stanford University, the 2017 Annual American Political Science Association, and 2018 Annual Midwest Political Science Association provided helpful feedback. We thank the editor and our three anonymous reviewers for providing us with additional comments. Lyall acknowledges financial support from the Air Force Office of Scientific Research (\#FA9550-14-1-0072) and the United States Institute for Peace (\#SG-446-15). Zhou acknowledges support from the National Science Foundation (SES.1148900). This research received institutional review board (IRB) approval from Princeton University (\#7280) and Yale University (\#1506016047). All errors and omissions are our own. The views and findings expressed here do not reflect the official positions of AFOSR, Mercy Corps, USIP, or the US Government. The authors declare they have no conflicts of interest. Our Pre-Analysis Plan was archived in the Evidence in Governance and Politics (EGAP) repository (\#20150928AA). Replication files, including $\mathrm{R}$ code and data, are available at the American Political Science Review Dataverse (https://doi.org/10.7910/DVN/AQHPTT).

Received: April 5, 2018; revised: April 21, 2019; accepted: October 10, 2019; First published online: November 18, 2019.
$\mathbf{E}$ conomic aid is increasingly enlisted as a tool designed to win over the "hearts and minds" of civilian populations during wartime. Governments, militaries, and aid agencies have implemented dozens of economic interventions designed to influence support for combatants in conflicts as diverse as Yemen, Pakistan, Colombia, Somalia, Nigeria, and the Democratic Republic of the Congo (Holmer and Bauman 2018; Pandith 2019; World Bank 2012). Billions of dollars have been spent in Afghanistan and Iraq alone in the belief that aid can persuade individuals to resist insurgent appeals and support counterinsurgency efforts (Berman, Shapiro and Felter 2011; Berman et al. 2011; Department of the Army 2014; Special Inspector General for Afghanistan Reconstruction 2014; Lyall, Shiraito, and Imai 2015; Sexton 2016). These aid interventions have taken various forms, including livelihood training, employment programs, cash-forlabor projects, and increasingly, direct cash transfers (Bastagli et al. 2016). Despite their disparate nature, these initiatives share the same basic premise: Economic assistance, if well-designed and -implemented, can bolster pro-government attitudes and stifle insurgent support, crippling a rebel organization's ability to attract new recruits or manufacture violence.

Yet credible evidence that these programs actually influence combatant support remains scarce. As one meta-analysis concludes, we still have few rigorous studies of these economic interventions in wartime settings (Zürcher 2017). ${ }^{1}$ Worse, we have almost no individual-level data from aid recipients themselves. Instead, existing studies have relied on observational or

\footnotetext{
${ }^{1}$ A growing literature has taken up the question of whether government transfers (including cash) increase public support, albeit almost exclusively in non-conflict settings. Evidence that these transfers win support is mixed. See, for example, Evans, Holtemeyer, and Kosec (2019); Manacorda, Miguel, and Vigorito (2011); Zucco (2013).
} 
quasi-experimental research designs at the subnational level to identify the presumed link between aid, attitudes, and violence (Berman, Shapiro, and Felter 2011; Berman et al. 2011; Crost, Felter, and Johnston 2014, 2016; Dasgupta, Gawande, and Kapur 2017; Lyall 2019; Nunn and Qian 2014; Weintraub 2016). While valuable, these studies do not examine whether aid improved livelihoods or influenced support for the government at the level where the aid is delivered. Ironically, existing hearts and minds theories often have no measures of hearts and minds; civilian attitudes are imputed from observed changes in insurgent violence rather than from measures of aid beneficiaries' attitudes toward the combatants. The few individual-level studies that do exist focus on at-risk men in post-war settings such as Burundi and Liberia, where dynamics of potential rebellion are different than active conflict settings (Blattman and Annan 2016; Gilligan, Mvukiyehe, and Samii 2012).

We therefore take up the question of whether and how aid can affect individual attitudes toward combatants ("combatant support") in wartime. To do so, we experimentally evaluate Mercy Corps' Introducing New Vocational Education and Skills Training (INVEST) program in Kandahar, Afghanistan. INVEST sought to improve the economic livelihood of marginalized youth in a context marked by high unemployment, weak government presence, and ongoing insurgency using two familiar staples of hearts and minds programming: vocational training (TVET) and unconditional cash transfers (UCT). ${ }^{2}$ Our evaluation provides the opportunity to test the presumed connection between aid and attitudes in a real-world, wartime setting where both the Afghan government and the Taliban are vying for the support of the local population.

We use a factorial randomized control trial design to assess the effects of this vocational training and a onetime unconditional cash transfer of US $\$ 75(5,163$ Afghanis) distributed via a mobile-phone electronic banking system (M-Paisa). Our sample consists of 2,597 at-risk men and women who were deemed vulnerable due to their age (20 years old on average), high unemployment, shared Pashtun ethnicity with the Taliban, and experience with forced displacement; just over half lived in internally displaced persons (IDP) camps or informal housing arrangements on the outskirts of Kandahar City and in three neighboring districts. As part of our empirical strategy, we draw on two indirect survey techniques-endorsement and randomized response experiments-to reduce preference falsification and strategic non-responses to sensitive questions about combatant support. To date, the potential of these techniques as measurement tools remains untapped within randomized evaluation studies.

Our findings cast a somber light on the ability of standard aid interventions to improve economic livelihood or alter the calculus of combatant support. First,

\footnotetext{
${ }^{2}$ For Mercy Corps' description of INVEST and its objectives, see "Does Youth Employment Build Stability?" https:/www.mercycorps.org/ research-resources/does-youth-employment-build-stability.
}

we find that vocational training barely improved economic livelihoods and had little discernible effect on pro-government sentiment. Second, cash transfers failed to generate lasting economic effects. Instead, they created a "boom and bust" dynamic, one marked by an immediate spike in pro-government sentiment followed quickly by a sharp reversal that led recipients to report increased support for the Taliban, including greater willingness to donate financially to its cause. Cash transfers also increased anger toward the government and led to more frequent disputes with police and local leaders. Third, we find that beneficiaries who received cash transfers, conditional on vocational training, reported increased support for the government up to eight months after INVEST concluded. These political gains were achieved despite the absence of any improvements to beneficiaries' economic well-being.

The paper is organized as follows. First, we identify two main channels through which aid might affect wartime attitudes that are consistent with the theoretical logic of hearts and minds arguments. One is a direct income-based channel in which aid affects individual (or community) livelihood, generating gratitude toward the government. The other channel is informational: Governments can claim credit for the aid to signal commitment to a given area, and locals therefore update their beliefs about the government's intent, capacity, and, ultimately, legitimacy. We then detail the nature of INVEST, including its purpose, quality, and cost. Next, we overview our experimental design, including randomization protocol, recruitment, and summary statistics on INVEST participants. We then discuss our empirical strategy before turning to the main findings, where we pose two related questions: (1) What effects did INVEST have on beneficiaries' net income and general economic well-being? And (2) how were patterns of combatant support changed, if at all, among individuals who received vocational training, cash transfers, and the combined UCT-TVET package? We then explore the nature of the "backlash effect" observed among UCT recipients. Finally, we discuss issues of attrition and alternative explanations before concluding with implications for scholars and policymakers.

\section{THEORIZING HOW AID SHAPES COMBATANT SUPPORT IN WARTIME}

Civilians, or, more specifically, their attitudes toward warring parties, occupy a central role in current hearts and minds theories of violence during insurgencies and civil wars (Beath, Christia, and Enikolopov 2011; Berman, Shapiro, and Felter 2011; Condra and Shapiro 2012; Department of the Army 2007; Lyall, Blair, and Imai 2013; Mikulaschek, Pant, and Tesfaye 2016; Hirose, Imai, and Lyall 2017). Civilian attitudes toward the combatants are thought tightly coupled with subsequent behavior: win over hearts and minds, and behavior will follow. In this model, individuals with pro-government leanings will be more inclined to provide information 
about insurgent identities and actions and to withhold material support from them. As a result, insurgencies face greater difficulties in recruiting and operating as "tips" flow from civilians to the government. Conversely, individuals who support the insurgency make it more lethal by sharing information about government movements, providing money, food, weapons, and shelter, and, at the extreme, even taking up arms against the state.

This model of wartime violence implicitly assumes that civilian attitudes are malleable and constantly subject to reevaluation. As the U.S. Army's field manual declares, "people pursue essential needs until they are met, at any cost and from any source. People support the source that meets their needs (Department of the Army 2007, 98). Individual decision-making is treated as unconstrained by prewar attachments, whether ideological or ethnic in nature. Driven by survival needs, wartime support is subject to capture by the side that provides the most compelling mixture of security and economic assistance. The stakes are therefore high; if the counterinsurgent can correctly identify the combination of aid and security, then it can win over local populations, eroding insurgent warmaking capacity. Civilian attitudes thus provide the microfoundation for both local patterns of violence and aggregate outcomes, including whether the counterinsurgent wins the war.

We focus on the first step in this causal sequence, namely, that aid affects civilian attitudes toward the combatants. We define combatant support as the degree to which an individual identifies with, and gives assistance to, a particular belligerent (here, either the government or an insurgent organization) instead of its armed rival during wartime (Beath, Christia, and Enikolopov 2011; Blair et al. 2013; Blair, Imai, and Lyall 2014; Lyall, Blair, and Imai 2013; Mikulaschek, Pant, and Tesfaye 2016). Combatant support consists of two components: (1) the degree of attitudinal alignment with the political agendas of warring belligerents and (2) the degree to which an individual is willing to undertake actions to render material assistance to a given combatant. These actions range from low risk (providing food or monetary assistance) to high risk (engaging in attacks against enemy forces). Following the existing literature, we conceptualize combatant support as zerosum in nature, with increases in government support coming at the expense of insurgent organizations and vice versa. $^{3}$

Existing theories suggest that aid shapes attitudes through a direct, income-related channel. Positive income shocks, whether at the individual or community level, are thought to generate gratitude toward the government, which reaps the credit for improved livelihoods in the form of increased support among beneficiaries (Berman, Shapiro, and Felter 2011). In this view, civilians are able to identify donors and assign credit correctly. Gratitude is also durable, either

\footnotetext{
${ }^{3}$ We do recognize, however, that support may be asymmetrical in nature under some conditions (Lyall, Blair, and Imai 2013); we leave an exploration of these two-sided dynamics to future work.
}

because aid produces lasting changes to income or the promise (or hope) of additional future aid sustains progovernment views. Insurgents could, however, outbid the government for civilian support by increasing their own aid efforts to surpass government efforts. This view of civilian decision-making is consistent with broader opportunity cost models in which participation in armed rebellion follows a simple utility-maximizing calculus. Poverty in particular leaves individuals vulnerable to insurgent propaganda; aid counteracts these appeals by raising an individual's costs of supporting or joining the insurgent organization (Becker 1968; Blattman and Annan 2016; Collier and Hoeffler 2004; Popkin 1979). Aid thus lifts incomes, creates gratitude, and bolsters pro-government sentiment.

Positive net income changes may also reshape an individual's preferences for order and stability. By raising incomes, aid can, for example, create incentives for lawful work rather than rebellion. Aid can also ease credit constraints that prevent economic advancement; cash transfers are especially valued for their ability to lift both present and future credit constraints by facilitating investment in income-generating activities. Welfare improvements not only allow individuals to better resist insurgent recruitment, they also lead individuals to place greater value on the conditions necessary for continued prosperity. Aid recipients may therefore cast their support behind the government if insurgents are viewed as a threat to these material gains.

While this direct income-channel between aid and combatant support is plausible, a second, largely overlooked, pathway is also possible. The act of providing aid itself might generate political effects indirectly via new information that leads individuals to update their beliefs about the government. Aid can act as a signal of the government's commitment to a given population, the selected area is important, and the locals have not been abandoned by the state. This signal is especially informative in wartime, where potential beneficiaries live in conditions of high uncertainty and low information about their government's intentions, competence, and capabilities. In fact, the government may be largely absent from the area; civilians may have had little or no direct contact with government representatives or local politicians due to security concerns that keep them from residing in, or even visiting, these locations.

As such, aid initiatives will typically be accompanied by extensive efforts by political leaders to claim credit for these programs (Cruz and Schneider 2017; Dietrich, Mahmud, and Winters 2018; Dietrich and Winters 2015; Evans, Holtemeyer, and Kosec 2018; Guiteras and Mobarak 2016; Winters, Dietrich, and Mahmud 2017). Politicians may visit field sites, deliver speeches, and otherwise "brand" these projects in an attempt to use them as evidence of their skill and ability to provide for their constituents. These efforts to reap the political rewards of economic programs can occur independent of the program's actual performance. Compared to the income-related channel, what matters here is that the aid is promised and delivered, not its actual effect on economic livelihood, since the aid itself is taken as 
evidence of the government's care for its citizens. In this model, civilians reward effort.

Foreign-funded aid projects are a particularly powerful signal to the local population, for several reasons. First, they boost the perceived competence of politicians involved because they managed to "capture" funds from foreign donors. In Bangladesh, for example, beneficiaries reported increased confidence in their local government once a USAID-funded project was revealed as foreign in origin (Dietrich, Mahmud, and Winters 2018). Similarly, in northeastern Afghanistan, villages with higher levels of foreign-funded infrastructure projects were associated with greater support for the district and provincial government than government-funded projects (Zürcher 2010). Second, foreign-funded programs rely heavily on local consent and cooperation, boosting the visibility of local politicians while creating additional opportunities for credit claiming. Third, perceptions of foreign involvement send positive signals about program quality, increasing the credit that accrues to the government for delivering these programs (Winters, Dietrich, and Mahmud 2017).

Viewed from the recipients' perspective, the introduction of a highly visible aid program to a violent setting opens a window in which individuals can reassess prior beliefs about the government and insurgency. Aid programs are thus venues for updating beliefs since they generate new information about the government's aims and its perceived competence through repeated interaction between politicians and locals. From these interactions, individuals can form broader judgments about the government's performance, its staying power in a given area, and its legitimacy. In short, the act of delivering (foreign) aid can itself affect combatant support independent of any possible improvements to net income or economic livelihood that these programs might generate.

\section{Hypotheses}

We derive several testable hypotheses about how aid affects wartime combatant support from these incomeand information-centric accounts. ${ }^{4}$ For the direct income channel, we anticipate that aid should first improve the economic livelihoods of recipients and thereby increase government support more than similar individuals who did not receive aid. While existing accounts are largely silent on the elasticity of political support, we expect that the greater the increase in a recipient's net income, the greater the increase in relative support for the government. Similarly, the timing of the anticipated changes is left unspecified in current theories. We hypothesize that cash transfers should have an immediate effect on pro-government attitudes given that they represent a sudden positive shock to personal net income. The positive effects of vocational training likely take longer to materialize; recipients need time to find employment after

\footnotetext{
${ }^{4}$ In this discussion, we assume that the aid program was well-designed and -implemented.
}

graduating. While we do expect increased government support after both types of aid, it is likely a bridge too far to expect that aid leads individuals to withdraw their support from the insurgency completely. The magnitude of the shift toward the government is thus somewhat constrained and unlikely to reach full support, at least with a single economic intervention.

For the information channel, we expect that aid recipients will record higher support for the government regardless of whether the aid (positively) affected their economic livelihoods. ${ }^{5}$ Similarly, we anticipate that the greater an individual's participation in a program, the larger the increase in pro-government sentiment. For example, as the program's duration lengthens and its intensity (measured in terms of time commitment) increases, the greater the opportunities for updating beliefs through frequent interaction with government representatives. In addition, complex interventions, e.g., those that combine multiple types of aid, may generate greater support for the government than simpler, single-shot interventions. Programs that blend different forms of aid increase the opportunities for credit-claiming by politicians. They also permit individuals to revise their assessments of government performance by cross-validating their judgments across different types of interventions. Two similar interventions are therefore less informative for participants than a compound intervention that mixes short- and medium-term programs of varying intensity and time commitment. As an auxiliary hypothesis, we should observe politicians and government representatives investing in public efforts to draw a tight connection between themselves and aid delivery.

Aid is likely to have heterogeneous effects based on individual traits. For example, the income channel view of persuading civilian attitudes suggests that the largest pro-government shifts in attitudes should be found among at-risk individuals who are unemployed, face severe credit constraints, and have few or no labor market skills. Similarly, we expect that individuals who have experienced displacement or physical harm by insurgents will be the most receptive to aid programs. Additionally, gender can dictate the nature of an individual's social network and thus condition the nature and frequency of his or her interactions with combatants (Parkinson 2013).

We treat the income and information channels as two components of a broader hearts and minds theory of civilian attitudes. Income and information may both shape attitudes; they are not necessarily exclusive. They are, however, analytically distinct. The informational account does not require any positive changes in personal net income for attitudes to swing toward the government. By contrast, the income channel presumes that positive shifts for the government only occur when economic livelihood is improved by the aid package. Aid may not work as intended, of course. Attitudes may not be driven by income at all but are instead shaped by

\footnotetext{
${ }^{5}$ This credit claiming argument was not explicitly detailed in our preanalysis plan. This discussion, along with associated empirical tests, should therefore be treated as speculative in nature.
} 
coethnic bias or prior harm at the hands of the combatants, swamping aid's effects. Aid may also backfire, first raising expectations and then dashing them, either due to poor execution, unintended consequences, or insufficient aid (e.g., the cash transfer was too modest to shift beliefs). Increased exposure to the government can drive home the reality of its poor performance, sowing doubts about its ability to defeat the insurgency or its commitment to locals. In this case, foreign aid may undermine government support if it fails to meet popular expectations.

\section{THE INVEST PROGRAM}

Mercy Corps' INVEST intervention was designed to improve the economic livelihoods of vulnerable youth, allowing us to test the proposed link between aid and attitudes at close-range. The Technical Vocational Education and Training (TVET) component sought to create new opportunities for increased and more lucrative employment, thus raising the cost of lost earnings if an individual was apprehended while fighting as an insurgent. In addition, TVET aimed to create new prosocial networks that would steer individuals away from the insurgency, reducing their exposure to insurgent recruitment. Unemployment in particular looms large in Mercy Corps' view of the root causes of Taliban recruitment success. "Unemployment is the main reason toward such actions [joining the Taliban] by the youth," one Vocational Training Center (VTC) director noted, "Because they cannot find jobs in the society in which they live ... unemployment gives birth to thousands of other evils. They find an alternative job with the insurgent groups, where they are given [a] weapon, a motorcycle, and a salary as well." ${ }^{, 6}$ He also noted the high-stakes nature of vocational training efforts in Kandahar. "If the government fails to find jobs for youth," he noted, "the consequences would be severe. These youth would turn toward drugs and may join anti-government militant groups." "Interviews with Mercy Corps staff and INVEST graduates confirm that Taliban recruitment efforts are pervasive in Kandahar, particularly among displaced individuals. Support for the Taliban was also judged as "quite high" by program designers, due in part to financial rewards for joining the Taliban but also driven by grievances against the government. ${ }^{8}$

The INVEST program consisted of three livelihood training components bundled together and an unconditional cash transfer. First, participants were enrolled in either three- or six-month TVET courses at one of four VTCs. These courses ranged from motorcycle and mobile phone repair to metal works and computer services to tailoring and English-language tutoring. The full list of nearly 40 courses is shown in Section $\mathrm{S} 3$ in the

\footnotetext{
${ }^{6}$ Interview, VTC Coordinator, Kandahar City, December 24, 2016.

${ }^{7}$ MoLSAMD Director, Aino Mina VTC, Kandahar City, Kandahar, December 26, 2016.

${ }^{8}$ Estimates vary, but Taliban salaries in Kandahar generally range from US $\$ 15$ to $\$ 25$ per month, though many fighters do not receive regular payments.
}

Supplementary Information (SI). While content was trade-specific, each course aimed to build practical marketable skills and to improve prospects for full-time employment in the local economy. Second, students were concurrently enrolled in a "soft skills" course designed to bolster business skills and employment opportunities by networking with key local market actors. As part of this course, participants received instruction in time management, decision-making, leadership, and negotiation. Third, participants who successfully completed technical TVET courses were provided with a small start-up kit of trade-specific tools upon graduation.

The second intervention was a one-time unconditional cash transfer of US\$75 (5,163 Afghanis) distributed via MPaisa, a cellphone-based electronic banking and payment system. This sum represents a large economic shock to a recipient's finances, equaling approximately fourmonths wages for the average unskilled male laborer in Kandahar. Indeed, this may underestimate its magnitude for the study population; three-quarters of INVEST program participants reported earning no net income in the month prior to enrollment. Our cash transfer also exceeds the US\$60 (4,089 Afghanis) annual allowance given to households in IDP camps by UNHCR and MoRR (Amnesty and International 2016). Cash transfers were completed two weeks prior to Endline 1. As part of this treatment, all INVEST participants were provided with a Roshan Telecom Afghanistan SIM card as well as in-person M-Paisa training. SMS messaging was used to alert individuals to M-Paisa training sessions, to their random selection into the cash transfer, and to the anticipated disbursement dates. Follow-up messages were also sent after the disbursement to individuals who had yet to withdraw their funds to ensure they were not facing technical or cognitive challenges in doing so. Frequent messages were required at all notification stages given persistent gaps in cellular phone coverage in Kandahar. Our SMS announcements about the cash transfer and endline surveys also reinforced the appearance of government involvement. Mercy Corps required an explicit statement in each message that it was not the donor of the cash funds. Instead, we informed INVEST participants that a "foreign donor" had provided the funds. This messaging may have created the opportunity for officials to claim credit for capturing explicitly foreign funds. ${ }^{9}$

In short, the INVEST program combines a plausibly at-risk population with economic interventions aimed at increasing income, providing the chance to explore if and how changed economic circumstances shift support for the Taliban and Afghan government. There are limits to the intervention, however. Mercy Corps could not guarantee that INVEST participants would secure full-time employment, and so the intervention is best thought of as a one-time shock to employability rather than employment. The actual time constraint imposed by attending the vocational classes was also modest, occupying at most six hours per day. Mobilization as

\footnotetext{
${ }^{9}$ Ethical concerns about deception prohibited falsely assigning credit to the government for the cash transfer.
} 
a full-time insurgent may be compatible with this schedule; an individual may not have to withdraw from the formal sectors of the economy to remain an active fighter (Berman et al. 2011). Similarly, the unconditional cash transfer did not impose a time constraint. UCT beneficiaries could also simply have pocketed these funds while remaining passive supporters or active fighters in the insurgency. That said, we maintain that the INVEST program was substantial enough to affect an individual's net income, if only temporarily, and that it offers a plausible vehicle for testing the connection between livelihood changes and combatant support.

\section{Program Quality}

Prior studies of TVET-style programming in developing countries, albeit in peaceful settings, have concluded that program quality, alongside suitability for local market conditions, plays an important role in determining whether these programs have their intended effects. ${ }^{10}$ If Mercy Corps' vocational training and the UCT were poorly designed or executed, it would be unsurprising if they produced no positive effects on either economic outcomes or attitudes toward combatants. We believe, however, that both interventions were generally welldesigned and well-executed and that they were appropriate for Kandahar's labor market. In our view, it is reasonable to expect that these programs were of sufficient quality and design to have their intended effects.

Mercy Corps, for example, involved local government officials and stakeholders in its TVET programming at the design stage to ensure it was tailored for the Kandahar market. Four rounds of similar TVET programming had already been successfully completed in neighboring Helmand province, while our evaluation coincided with the third of four planned TVET waves in Kandahar. As a result, Mercy Corps' local staff had gained considerable experience implementing its TVET programming in this environment, helping to reduce missteps that might compromise the quality of project implementation. In a series of post-graduation focus groups, our INVEST participants repeatedly emphasized that they believed the program was reasonably well-run and that they had acquired new skills that increased their employability, if not full-time employment. "I was satisfied with everything from the teaching syllabus to the environment of this VTC," 11 one graduate remarked. Female graduates were particularly enthusiastic. As one graduate said, "the people who have started this skill learning center have done a great job. Everyone, especially poor people, can learn skills and earn some income. I wonder what can be better than this?"12 In fact, the most frequent complaint

\footnotetext{
${ }^{10}$ Evidence of TVET effects on skills uptake, employability, and employment in developing countries is mixed. Some studies find dramatic positive effects (Alfonsi et al. 2017); others, more modest but persistent effects (Attanasio et al. 2017); and still others find little or no effects at all (Hirshleifer et al. 2015). For a review, see McKenzie (2017).

${ }^{11}$ Participant 7, Aino Mina Focus Group (Red Group), December 24, 2016.

12 Participant 3, Aino Mina Focus Group (Yellow Group), December 24, 2016.
}

expressed in these focus groups was that the three-month program was too short; many desired longer programs to acquire even more skills in their chosen craft. ${ }^{13}$

Despite initial difficulties at the registration phase (see below for details), the UCT was delivered on time and without technical glitches. Several pre-transfer notifications were sent to intended recipients to set expectations about the transfer's size and estimated arrival date. These notifications also stressed that the UCT was a one-time affair. We noted only isolated instances of individuals seeking Mercy Corps' assistance in accessing the funds and received positive feedback from both Roshan and participants about the quality of its M-Paisa training. Roshan also provided detailed data indicating the date and time of the cash receipt for each individual as well as withdrawals for six months after the UCT was received. Given the electronic nature of the disbursement, we are confident that the funds were delivered to the intended recipients, thus creating a realistic possibility of alleviating their specific cash constraints.

\section{Cost}

Mercy Corps estimated the cost (excluding fixed costs such as renting training facilities, main office expenses, and security) of INVEST at about US\$229 $(15,600$ Afghanis) per individual in 2016. An additional US $\$ 80$ (5,450 Afghanis) per individual was associated with the cash transfer (US\$75) and SIM card purchase (US\$5 per card). These program costs exceed Afghanistan's flagship development campaign, the National Solidarity Program, which capped the size of its community grants at US $\$ 200$ (13,624 Afghanis) per household. ${ }^{14}$ INVEST was, however, far less expensive than similar efforts in postwar Liberia, where AoAV spent US\$1,275 per individual to provide vocational training for high-risk men engaged in criminal activities (Blattman and Annan 2016).

\section{EXPERIMENTAL DESIGN}

We use a factorial randomized control trial design with a waitlist (oversubscription) recruitment method to evaluate the INVEST program. We conducted two endline surveys to evaluate INVEST; Endline 1 occurred two weeks after the UCT distribution at the end of training (April 27 to May 14, 2016), and Endline 2 eight months later (November 10 to December 5, 2016).

\section{Recruitment}

INVEST targeted at-risk populations in Kandahar City, Afghanistan's second largest city (population: 600,000), as well as internally displaced persons in neighboring districts of Dand, Daman, and Arghandab. It was administered by Mercy Corps in four government-owned

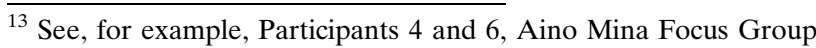
(Red Group). Men were far more likely to complain about the threemonth program's duration than women.

${ }^{14}$ Unlike INVEST, the NSP was designed to provide public goods, not individual-level benefits (see Beath, Christia, and Enikolopov 2011).
} 
VTCs in Kandahar City. Mercy Corps sought to provide INVEST to 12,000 individuals over four waves. Recruits were individually identified by a consortium of actors: Mercy Corps, three provincial Departments-the Department of Refugees and Repatriation (DoRR), the Education Department, and Ministry of Labor, Social Affairs, Martyrs and Disabled (MoLSAMD), the United Nations High Commissioner for Refugees (UNHCR), village councils (shuras), local leaders, and tribal elders. In total, 2,597 individuals were recruited into our INVEST study. We have no data on individuals who were deemed ineligible for participation. Although we cannot rule out the possible existence of unobserved factors influencing the recruitment process, we received no reports about Taliban intimidation of recruits. Figure 1 shows demographic summary statistics of our participants, and it indicates that the selection process produced a pool with the desired traits, namely "at-risk" individuals who were young, underemployed, poor, and displaced. Participants were assigned to a single VTC for the program's duration based on gender and proximity to their homes. ${ }^{15}$

\section{Randomization}

To maximize statistical power, block randomization was used to assign treatment or control status to our 2,597 participants (Imai, King, and Stuart 2008). We first blocked on training site given their differences in gender composition and travel distance. ${ }^{16}$ Participants registered at the most convenient VTC. Within each training site, we blocked on three- versus six-month vocational courses. In addition, we blocked on gender for the Aino Mina VTC, which served both female and male participants. This yielded 10 blocks in total. We then created groups of four within each block matching on employment status, displacement status, and exposure to violence during the past year. These data were collected on the pre-baseline enrollment form. Finally, within each group of four, we randomly assigned treatment to one of four types (TVET treatment-UCT treatment, TVET treatment-UCT control, TVET control-UCT treatment, and TVET control-UCT control). Participants were not informed of their treatment status until after the baseline survey was completed.

We encountered a logistical issue with UCT registration, however, that forced a deviation from the standard factorial design. ${ }^{17}$ Due to unfortunate clerical errors, we were only able to match the Mercy Corps INVEST unique identifiers with Roshan-supplied identifiers for its M-Paisa training for 1,168 individuals (45\% of all participants) by March 2016. Given this reduction in sample size and the possibility of selection bias, we re-randomized the UCT treatment arm for these registered participants (the "UCT subset"). To be clear, we did not lose the individuals in the "non-

\footnotetext{
${ }^{15}$ Participants commuted up to 45 minutes daily between their homes and the assigned VTC.

${ }^{16}$ The four VTC locations were Mirwais Mina (male only), Sufi Sahib (male only), Mahmood Tarzai (female only), and Aino Mina (mixed).

17 This change was recorded in our PAP.
}

UCT subset." They were still participants in the study, namely, through the TVET intervention. We simply could not identify them with Roshan, and thus, they became ineligible for the UCT intervention. ${ }^{18}$ We first blocked on TVET treatment status and gender. We then pair-matched individuals using VTC and prebaseline employment and displacement status. We discuss how this affects the interpretation of our estimates in the Empirical Strategy section. After rerandomization, 586 of the UCT subset were notified on April 22, 2016 that they had received their cash transfer. At Endline 1, 348 (59.4\% of those assigned to UCT treatment) had already acknowledged receipt by accessing their M-Paisa account at least once. Figure 2 summarizes our design, the sample sizes assigned to each group, and their proportion of the study participants. (Figure S1 in the SI details the timeline of the study.)

\section{DATA}

Data were collected via individual face-to-face interviews at the VTCs with enumerators using tablets and smartphones running Open Data Kit (ODK). Figure 1 shows that on average, the participants were 20.4 years old (median: 18 years) and unmarried (only $23.3 \%$ were married), two risk factors associated with insurgent recruitment. $79.3 \%$ self-identify as Pashtun, sharing ethnicity with the Taliban. They already had an average of 7.8 years of formal state education and 1.2 years of religious madrassa education, indicative of the large number of students enrolled or waitlisted for INVEST. The sample also reflects widespread economic vulnerabilities: Only $28 \%$ of the sample was employed at baseline, and average net income in the past month (defined as wages minus expenses) was only about US\$5 (336.88 Afghanis). Some $77.6 \%$ of the sample reported earning no net income at all during the past month; of those who did report a net income, the average amount was about US $\$ 20$ (1,408.98 Afghanis). 38.9\% rented their homes, while on average individuals had electricity for only three hours a day. Women comprise $36.2 \%$ of our sample $(n=940)$.

Our sample also reflects a high degree of exposure both to wartime violence and the belligerents themselves. Over half $(50.9 \%)$ report being forcibly displaced due to ISAF and Taliban combat operations. Given wartime conditions and unemployment pressures, it is unsurprising that $29.5 \%$ have a friend currently serving in the Afghan National Security and Defense Forces (ANDSF) while $24 \%$ have a friend who previously served in the ANDSF. By contrast, $10.3 \%$ have friends that regularly contribute financially to the Taliban. Some $8.4 \%$ openly acknowledge that they have friends who could find a Taliban recruiter easily. In short, these individuals' decisions about combatant support are not hypothetical; they reflect the need to make realistic

\footnotetext{
${ }^{18}$ For more details on the original treatment assignment and rerandomization, see Table S1 in the SI.
} 


\section{FIGURE 1. Participant Demographics at Baseline}
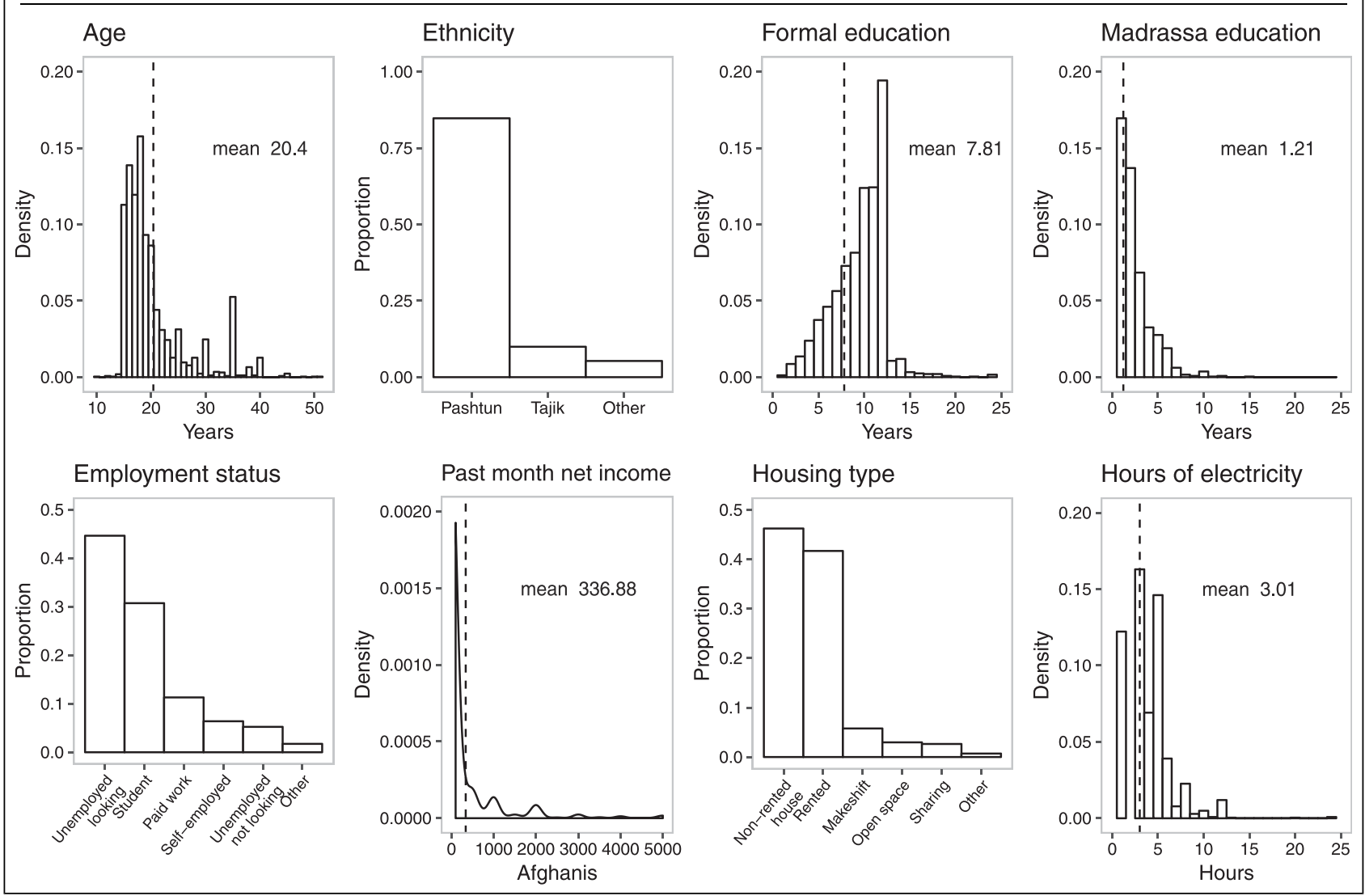

\section{FIGURE 2. Factorial Randomized Control Trial with Block Randomization}

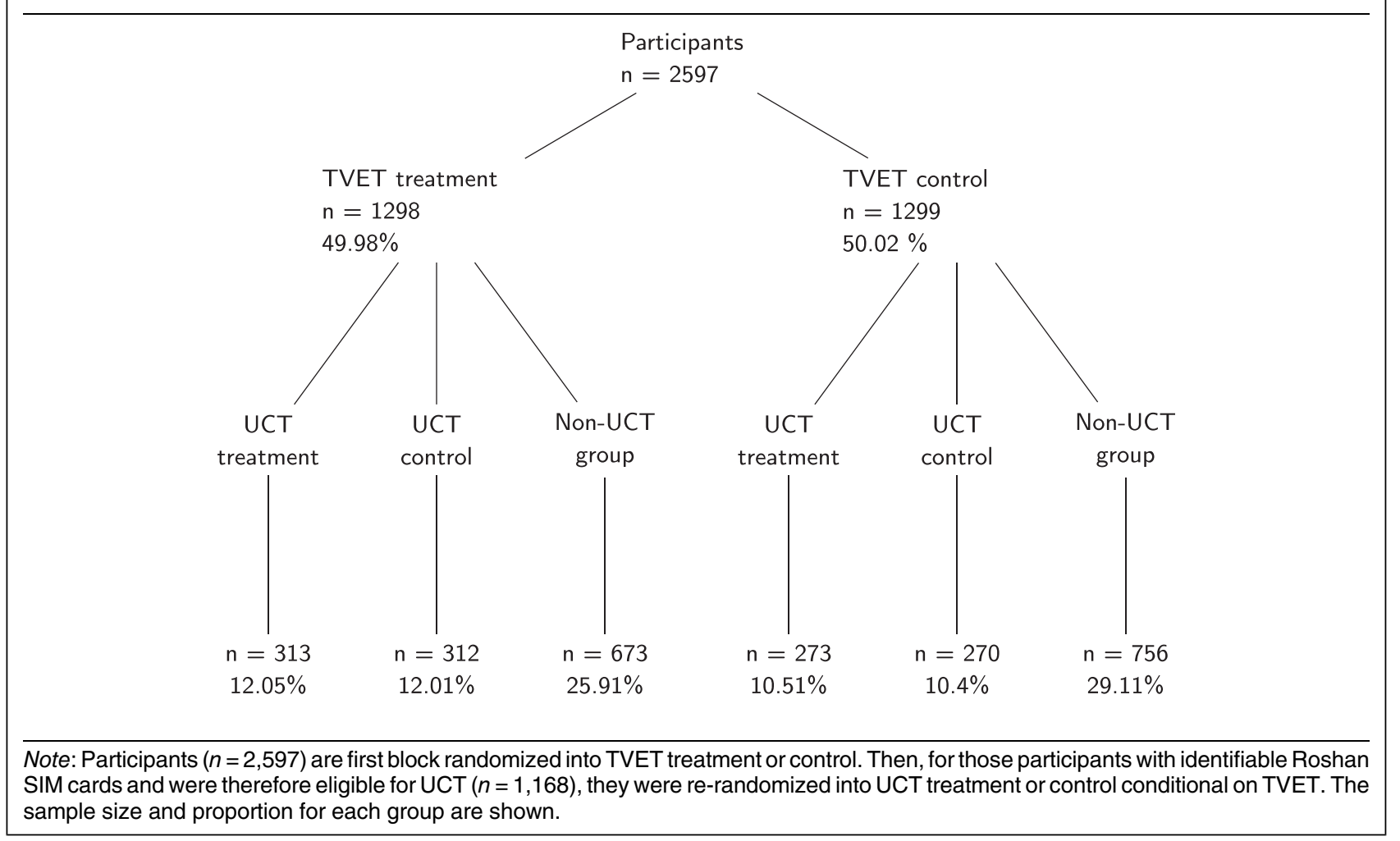


TABLE 1. Guide to Interpreting Effects

\begin{tabular}{|c|c|c|c|}
\hline & TVET treatment & TVET control & Decomposing the effects \\
\hline UCT treatment & A & $\mathrm{D}$ & TVET marginal: $(A+B+C)-(D+E+F)$ \\
\hline UCT control & $\mathrm{B}$ & $E$ & UCT marginal: $(A+D)-(B+E)$ \\
\hline Non-UCT group & $\mathrm{C}$ & $\mathrm{F}$ & UCT-TVET: $(A-B)-(D-E)$ \\
\hline
\end{tabular}

Note: Given the added complexity of the UCT re-randomization, this table provides a guide on how to interpret our main effects: TVET marginal, UCT marginal, and UCT-TVET. On the left side, each intervention group is labeled a through F, and the groups belonging to the nonUCT subset are shaded in dark gray. The right side lists each effect and of which groups they are composed.

calculations about whether and how much to support combatants active within their communities.

As expected, the sample is well-balanced across 20 baseline covariates and indices. Columns 3 and 6 of Table S3 in Section S4 in the SI report the average differences for the treatment group relative to the control group across these covariates for TVET and UCT recipients. These differences and their standard errors are calculated first within the 10 blocks and then averaged across blocks, weighted by block size. We use the t-statistic to report the $p$-values. For the TVET group, only one covariate is imbalanced at $p$-value $<$ 0.05 ; the treatment group has only 0.1 more personal assets than the control group; personal assets are measured on a 0 to 5 scale, summing over an individual's possession of a mobile phone, bicycle, motorcycle, automobile, and personal computer. There are no imbalances for the UCT group. Given the number of covariates, this suggests that our blocked randomization successfully generated well-balanced groups.

\section{EMPIRICAL STRATEGY}

For directly measured outcomes-such as employment, assets, and attitudes about violence-we estimate the intention-to-treat (ITT) effects using a nonparametric analysis approach based on the difference-in-means estimator, while taking into account the block randomization design. For the marginal ITT effects of either TVET or UCT, we calculate difference-in-means estimates within each of the 10 blocks and then take their average across the blocks, weighted by assigned block size. For the UCT-TVET interaction ITT effect, we estimate the average interaction effect which, due to our re-randomization of UCT conditional on TVET status, is the difference in the average effect of UCT conditional under TVET treatment condition versus under TVET control condition. This UCT-TVET effect is thus interpreted as the additional effect of UCT attributable to participation in TVET. Again, we calculate this within each of the 10 blocks and take the weighted average. Table 1 provides a guide on how to interpret these effects throughout the paper.

For outcomes of combatant support, we take a similar approach to the estimation, but since we used indirect survey techniques, we must also account for the experimental survey designs in our analysis. For the endorsement experiment, we model the probability of support for the Taliban versus the Afghan government using a hierarchical model with random intercepts by block. Additionally, for the randomized response questions, we estimate the ITT effects as a difference-inmeans by taking into account the forced response design parameters that determine the probabilities of whether respondents give forced or truthful answers (Blair, Imai, and Zhou 2015). Within each block, we nonparametrically estimate the average difference in the proportion of a "yes" response, and then, we take the weighted average of these within-block effects to obtain the overall ITT effect.

Next, we recognize that average treatment effects are useful summaries but can obscure important variation within our sample of INVEST participants. We therefore extend our ITT analysis to explore effects across two pre-specified characteristics thought to condition political attitudes and the prospects of insurgent recruitment: gender and experience of displacement (see Section S14 in the SI). ${ }^{19}$

Finally, we offer two additional analyses. To account for the noncompliance that exists in this evaluation, we conduct an instrumental variables analysis using the Neyman stratification method by calculating each component of the standard Wald estimator as a weighted average across the blocks in order to identify average treatment effects for compliers (CATE) (Angrist, Imbens, and Rubin 1996) (see Section S16 in the SI). We also use the R package $m i$ (Su et al. 2011) for multiple imputation to address concerns regarding attrition and non-response at Endline 1 and/or 2 (Little and Rubin 2002) (see Section S15 in the SI). ${ }^{20} \mathrm{We}$ further discuss the estimation of the indirect questions, UCT-TVET interaction effects, CATE, multiple imputation, and the construction of the randomized response indices in Section S9 of the SI.

\footnotetext{
${ }^{19}$ From the review process, we also include sub-group analyses by age, education, and 3- versus 6-month TVET courses. Please note, these analyses were not pre-registered in our PAP.

${ }^{20}$ We do not use the bounds analysis proposed by Lee (2002) because it requires the assumption of monotonicity: Treatment assignment can only affect sample selection in one direction. Simple two-sided T-tests in Section S5 of the SI show that we cannot reject the null hypotheses that those assigned to TVET or UCT treatments are no more or less likely to attrite than those assigned to control, with $p$-values 0.35 and 0.64 , respectively.
} 


\section{FIGURE 3. Intention-to-Treat Endline 1 (Top Panel) and 2 (Bottom Panel) Analysis of Employment Outcomes, with $95 \%$ Confidence Intervals}

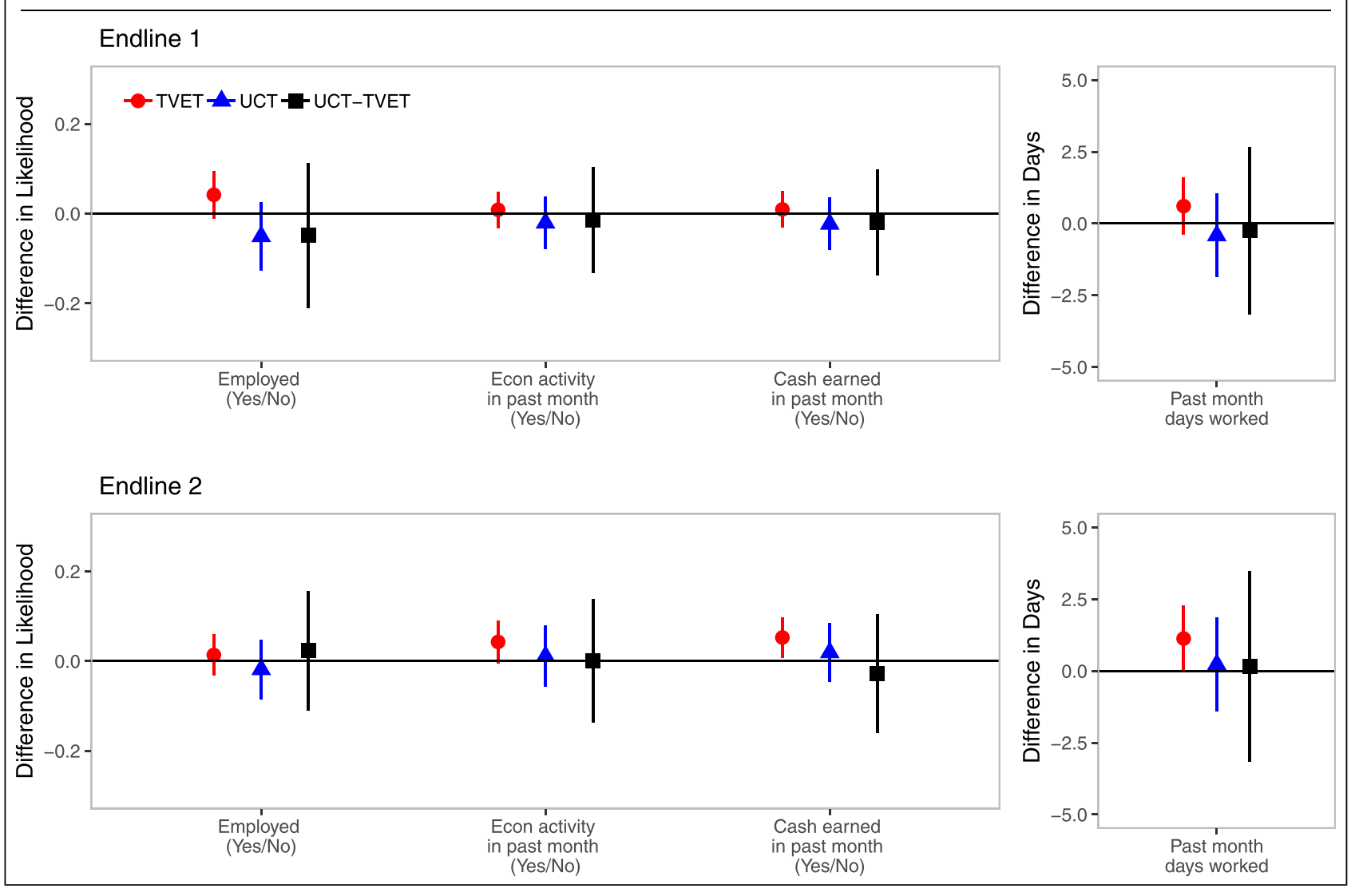

\section{FINDINGS}

Our empirical analysis proceeds in several stages. We first investigate participants' economic outcomes, then their patterns of support for the Taliban or Afghan government, and finally their attitudes toward violence more generally. ${ }^{21} \mathrm{We}$ provide intention-to-treat (ITT) estimates for the marginal effect of TVET (red circles), the marginal effect of UCT (blue triangles), and the UCT-TVET interaction effect (black squares). ${ }^{22}$ The vertical bar for each estimate represents its $95 \%$ confidence intervals.

\section{Economic Outcomes}

Did INVEST positively affect economic outcomes? Beginning with employment, Figure 3 demonstrates that there are some modest gains from participation in TVET. At Endline 1, there are no statistically significant

\footnotetext{
${ }^{21}$ With respect to concerns about multiple hypothesis testing, we use the Benjamini-Hochberg procedure to adjust for the false discovery rate (FDR) in Section S10 of the SI. We show that our results are robust.

${ }^{22}$ The UCT-TVET interaction effect equals the difference between the effect of UCT under TVET treatment condition and the effect of UCT under TVET control condition. We show these component estimates for all the figures in this paper in Section S12 of the SI.
}

effects of the interventions shifting employment outcomes. The picture improves somewhat at Endline 2. For TVET participants, the likelihood of having earned cash in the past month (binary indicator) is 5.3 percentage points higher $(95 \% \mathrm{CI}=[0.7,9.8])$. Additionally, the following results are suggestive but not significant at conventional levels: TVET recipients are 4.3 percentage points more likely $(95 \% \mathrm{CI}=[-0.4,9])$ to report some economic activity (a binary yes/no indicator) and 1.13 more days worked in the past month $(95 \% \mathrm{CI}=[-0.01,2.27])$. While these gains are modest, TVET does appear to have some positive economic effects, especially as time-from-graduation increases, which is reasonable given the need for time to look for work.

We also examine a five-fold portfolio of individual and household assets. Once again, we observe modest improvements, as illustrated in Figure 4. While at Endline 1, there are no statistically significant effects, by Endline 2, TVET recipients are 5.7 percentage points more likely $(95 \% \mathrm{CI}=[0.8,10.6])$ to be a landowner either formally through title deed or informally through rent. Again, the following results are suggestive but not significant at conventional levels: TVET recipients also have $0.08(95 \% \mathrm{CI}=[-0.01$, $0.17]$ ) more personal assets (scale of 0 to 5 ) and 0.17 $(95 \% \mathrm{CI}=[-0.04,0.39])$ more household assets (scale of 0 to 12 ). 
FIGURE 4. Intention-to-Treat Endline 1 (Top Panel) and 2 (Bottom Panel) Analysis of Asset Outcomes, with $95 \%$ Confidence Intervals

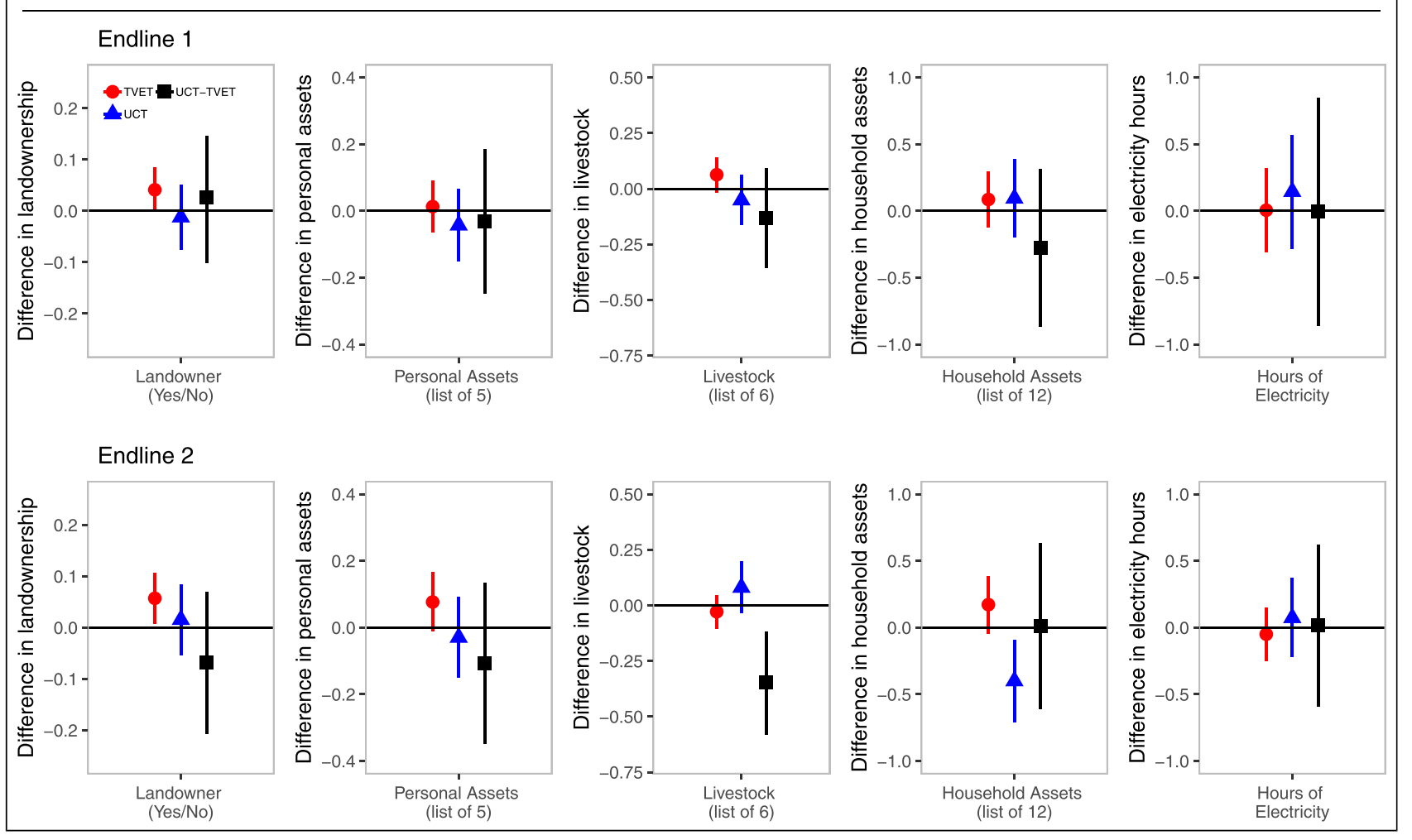

By contrast, the unconditional cash transfer appears to have had almost no effect on either personal net income or household assets at either Endline 1 or Endline 2. While there is weak evidence that UCT recipients have $0.08(95 \% \mathrm{CI}=[-0.03,0.2])$ more livestock (scale of 0 to 6 ) at Endline 2, they report -0.4 $(95 \% \mathrm{CI}=[-0.71,-0.09])$ household assets (scale of 0 to 12). The same bleak picture extends to the UCTTVET interaction effect. There are no observed positive economic effects across personal net income or household assets at either Endline, and they report 0.35 less livestock $(95 \% \mathrm{CI}=[-0.58,-0.12])$. Simply put, neither of these economic interventions is having the desired effect on participants' livelihood.

What might explain these dismal UCT outcomes, especially in combination with TVET? Drawing on Roshan data, we can identify the timing of cash transfer withdrawals and spending patterns. Cash transfer recipients overwhelmingly applied their windfall toward immediate consumption needs. Almost half $(45.4 \%)$ revealed that they spent the majority of their cash transfer on rent and housing needs, followed by food $(14.9 \%)$ and educational expenses $(14.2 \%)$. Few individuals reported starting a new business $(3.5 \%)$ or reinvesting their cash transfer into an existing one $(0.7 \%)$. Individuals typically withdrew their funds in a single transaction almost immediately upon SMS notification. As a result, the cash transfer was exhausted well before Endline 2. Given these spending patterns, it is unsurprising that the UCT failed to spark sustainable economic improvements.

\section{Combatant Support}

Despite the negligible effects of both vocational training and cash transfers on economic well-being, we cannot rule out the possibility that these interventions influenced an individual's support for the government and Taliban via the political logic of signaling. To answer this question, we adopt two indirect questioning techniques that prior research has demonstrated are effective at eliciting truthful responses in wartime conditions (Blair, Imai, and Lyall 2014; Lyall, Blair, and Imai 2013).

We first employ four endorsement experiments that are pooled to construct an estimate of relative support for the Afghan government versus the Taliban within the item response theory framework (Bullock, Imai, and Shapiro 2011). We then implement a forced-design randomized response experiment, which measures each individual's willingness to engage in a range of progovernment and pro-Taliban actions (Blair, Imai, and Zhou 2015; Blair, Zhou, and Imai 2015). Below, we briefly describe each method. We reproduce the endorsement experiment and randomized response questions and protocols in Sections S6 and S7 of the SI, respectively, where we also provide descriptive plots for each of the endorsement questions (Section S8).

Endorsement experiments are designed to measure an individual's implicit bias toward (or against) a specific actor. In this design, respondents are randomly assigned to a treatment group and then asked to express their opinion toward a policy proposal endorsed by particular actors - here, the Afghan government or the 


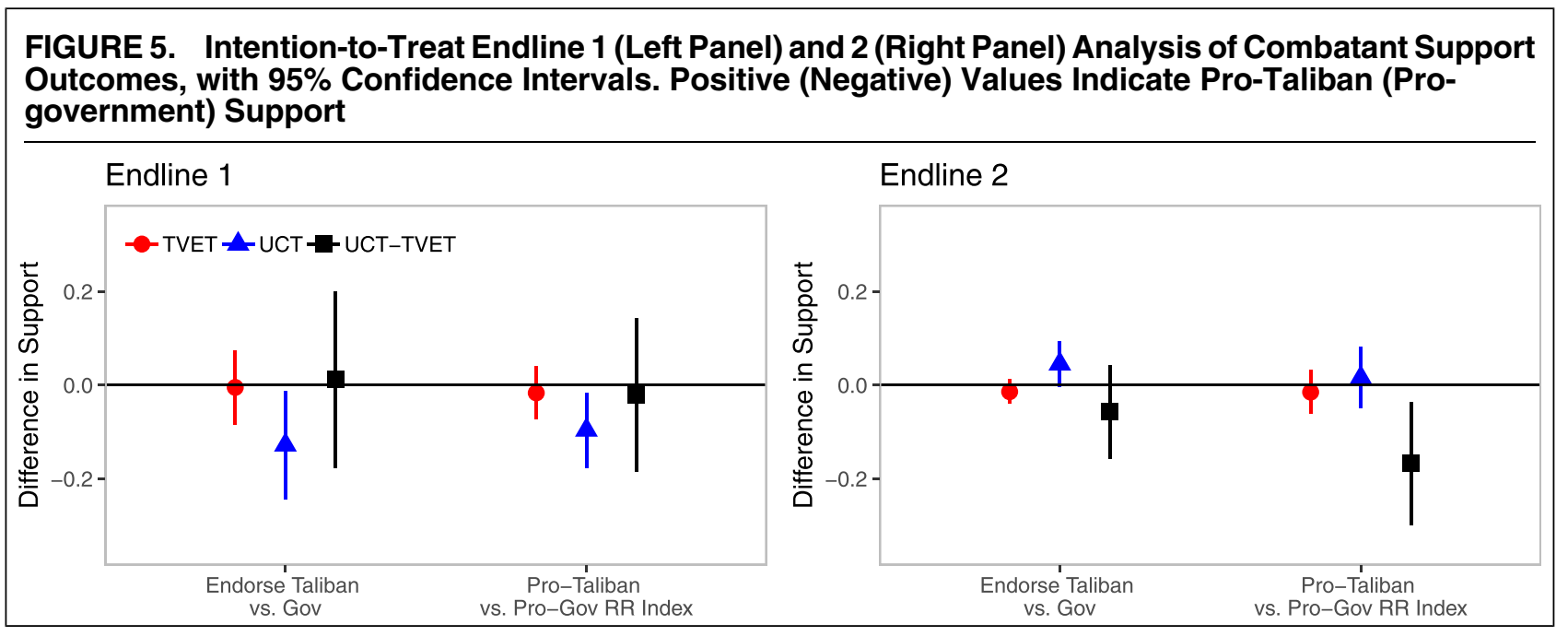

Taliban - whose support level we wish to gauge. For all four endorsement questions, respondents were asked to assess their level of support for each proposal on a fivepoint scale. $^{23}$

Each respondent is assigned only one treatment condition for each endorsement experiment. We thus cannot deduce any specific individual's relative support for these combatants. Instead, we aggregate responses across the policy proposals and interpret higher (lower) values as evidence of support for (against) each combatant. The subtle cue about the endorser's identity, buried within a longer policy question, avoids triggering social desirability bias and preference falsification, tapping into an individual's implicit views of the combatant. Since the proposed policies are held constant across different conditions, we also control for latent support for the policy itself, leaving the remaining differences in support attributable to the endorser's identity.

Next, randomized response experiments reduce social desirability bias through use of a randomization device-here, a spinner-which dictates whether the respondent is instructed to give a predetermined response. Each respondent is presented with a series of simple "yes"/"no" questions about their willingness to undertake pro-government and pro-Taliban behaviors. For each question, the respondent spins the spinner twice, unseen by the enumerator, and is instructed to follow the instructions based on the first spin. The spinner itself is divided into forced "yes," "no," and "answer truthfully" sections with known probabilities $(1 / 6,1 / 6$, and $2 / 3$, respectively). By introducing random statistical noise, the method conceals individual responses since the spinner's final location from the first spin is unknown to the enumerator. Respondents are therefore more inclined to answer truthfully since they

\footnotetext{
${ }^{23}$ The possible responses are: "I strongly agree with this proposal"; "I somewhat agree with this proposal"; "I am indifferent to this proposal"; "I disagree with this proposal"; and "I strongly disagree with this proposal." Respondents were also permitted to answer "Don't Know" or "Refuse to Answer."
}

know their answers cannot be identified or traced back to them. To prevent confusion about this method and ensure that respondents understood the underlying logic, we preceded our sensitive questions with several practice non-sensitive questions.

Using this forced-choice design, we ask about an individual's willingness to engage in five progovernment behaviors. These are: (1) paying greater taxes; (2) sending a pro-government SMS to friends and family; (3) providing information ("tips") about insurgent identities and actions to the government; (4) enlisting in the ANDSF; and (5) reporting corrupt government officials. We also asked about four proTaliban behaviors: (1) donating funds to the Taliban; (2) providing information about the identities and actions of government officials; (3) sending a pro-Taliban SMS to family and friends; and (4) sheltering Taliban fighters in one's home. ${ }^{24}$ We also constructed a single unweighted family index, combining all actions for each combatant ("Pro-Government Index" and "Pro-Taliban Index") by taking the average across the randomized response estimates for these sets of questions. To estimate relative support, we also calculated the differences between these two index measures, creating a relative measure ("Pro-Taliban Index vs. ProGovernment Index") in which positive values indicate greater willingness to undertake pro-Taliban actions.

We report our findings in Figure 5. Within each plot, the first set of estimates shows the average treatment effects (ATE) for the endorsement experiments, which refer to the average increase in the probability of expressing positive support for the Taliban relative to the Afghan government. The second set of estimates shows the randomized response Pro-Taliban vs. ProGovernment index measure, for which positive values represent an increase in the average effect on

\footnotetext{
${ }^{24}$ For safety reasons, we did not ask questions about current membership in the Taliban nor about participation in attacks against government forces or civilians.
} 
willingness to undertake pro-Taliban actions relative to pro-government actions.

Beginning with TVET recipients, we find that vocational training has no effect on relative support for these combatants at either endline. The same null effect holds when we consider the net difference in ProGovernment and Pro-Taliban indices at both endlines. These null effects at Endline 1 are perhaps unsurprising; training just ended for students in the six-month TVET programs when Endline 1 was conducted, while graduates of the three-month program had only three months to secure employment. At the first endline, then, graduates had little time to generate net income, the main mechanism by which TVET was designed to affect attitudes. Yet the persistence of the null effect at the seven-month mark, in which three-month TVET graduates had a full year to find steady employment, is problematic for claims that vocational training can shape attitudes.

By contrast, the UCT recipients recorded increased support for the government across both measures of combatant support at Endline 1. Cash beneficiaries reported -12.8 percentage points $(95 \% \mathrm{CI}=[-24.3$, $-1.2])$ in relative support for the Taliban only two weeks after UCT disbursement. Similarly, we find -9.6 percentage points in an individual's relative willingness to undertake pro-Taliban actions $(95 \% \mathrm{CI}=$ $[-17.6,-1.6])$ at the first endline using the randomized response questions. These effects are short-lived, however. By Endline 2, positive affect toward the government seems to have reversed itself, with UCT recipients now reporting 4.5 percentage point greater in pro-Taliban sentiment, although its $95 \%$ CI $([-0.4$, 9.4]) contains zero. No statistically significant effect estimate is obtained on an individual's relative willingness to carry out pro-government or pro-Taliban actions by Endline 2.

This backlash effect becomes even more stark when we decompose the UCT-TVET interaction effect into its two constituent components, the UCT-TVET treatment and UCT-TVET control recipients, meaning the effects of receiving UCT conditional on also receiving the TVET treatment or control, respectively. As shown in Figure S10 of the SI, the UCT conditional estimates resemble the UCT marginal estimates at Endline 1, and so the UCT-TVET interaction effect, which is the difference of the two conditional estimates, is close to zero. At Endline 2, however, the randomized response pro-Taliban versus pro-government measure for the UCT conditional on TVET control are proTaliban at 10.8 percentage points $(95 \% \mathrm{CI}=[1.4$, 20.2]). Individuals who are in the UCT-TVET control condition seem especially susceptible to sharp swings from pro-government to pro-Taliban sentiment between Endline 1 and Endline 2. Cash transfers untethered to vocational training therefore primed pro-government sentiment quickly but faded in the medium term, leaving behind increased support for the Taliban.

We do not find any statistically significant effects on combatant support for the UCT-TVET interaction at either endline when drawing on the endorsement experiments. Turning to the randomized response index measure on willingness to take actions on behalf of the Taliban versus the government, the estimated effect is also null at Endline 1. At Endline 2, however, this interaction effect is -16.7 percentage points, suggesting a reduction in the willingness to engage in pro-Taliban as opposed to pro-government actions $(95 \% \mathrm{CI}=$ $[-29.8,-3.5])$. This is one of the largest swings we find in support for the combatants across any treatment combination. Although not statistically significant, the endorsement measure points in the same direction at -5.7 percentage points $(95 \% \mathrm{CI}=[-15.7,4.3])$. Unlike UCT effects, the UCT-TVET interaction effect on political attitudes takes time to unfold but appears sustainable, at least eight months later, and manages to increase relative support for the government in ways unmatched by the TVET treatment arm alone.

Since we built multiple measures for pro-government and pro-Taliban actions, we are able to identify which elements of support may have been influenced by these treatments (see Section S12 of the SI). Lending credence to our claim that the UCT-TVET interaction has political consequences, when examining by sub-group, we note in Figure S23 of the SI that male UCT-TVET recipients displayed greater willingness to pay more taxes $(22.3$ percentage point increase, $95 \% \mathrm{CI}=[1.8$, 42.8]) and to enlist in the ANDSF (38.1 percentage points, $95 \% \mathrm{CI}=[16,60.3]) .{ }^{25}$ These tax findings are especially important as bellwethers of tax morale, which as an attitudinal outcome is known to predict the health of the fiscal contract between a government and its citizens (Paler 2013).

\section{Exploring the "Backlash" Effect of Cash Transfers}

Examining the possible backlash effect of UCT, we draw on two sets of direct questions asked at Endline 2 that measure attitudes (binary yes/no) and self-reported behaviors (scaled frequency) involving: (1) violence against the state and its representatives (political violence) and (2) violence toward community members (local violence).

First, the political violence outcomes in Figure 6 are "violence justified against unfair state," "how often had disputes with police," and "how often had disputes with a leader." Here we find increased anger toward the government among UCT recipients at Endline 2 but not among the TVET group or the UCT-TVET interaction group. Consistent with the expectation of antigovernment backlash, UCT recipients reported a 0.05 difference in frequency $(95 \% \mathrm{CI}=[0.01,0.09])$ of having major disputes with leaders over the past year. ${ }^{26}$ Suggestive but not statistically significant, UCT recipients also recorded a 0.06 difference in frequency $(95 \%$ $\mathrm{CI}=[-0.01,0.12])$ of major disputes with the police

\footnotetext{
${ }^{25}$ Increased willingness to join the ANDSF is driven by the UCTTVET treatment group; the UCT-TVET control group recorded a statistically significant decrease in willingness to enlist.

${ }^{26}$ This is a scaled index ranging from never (0) to rarely (1) to sometimes (2) and often (3).
} 


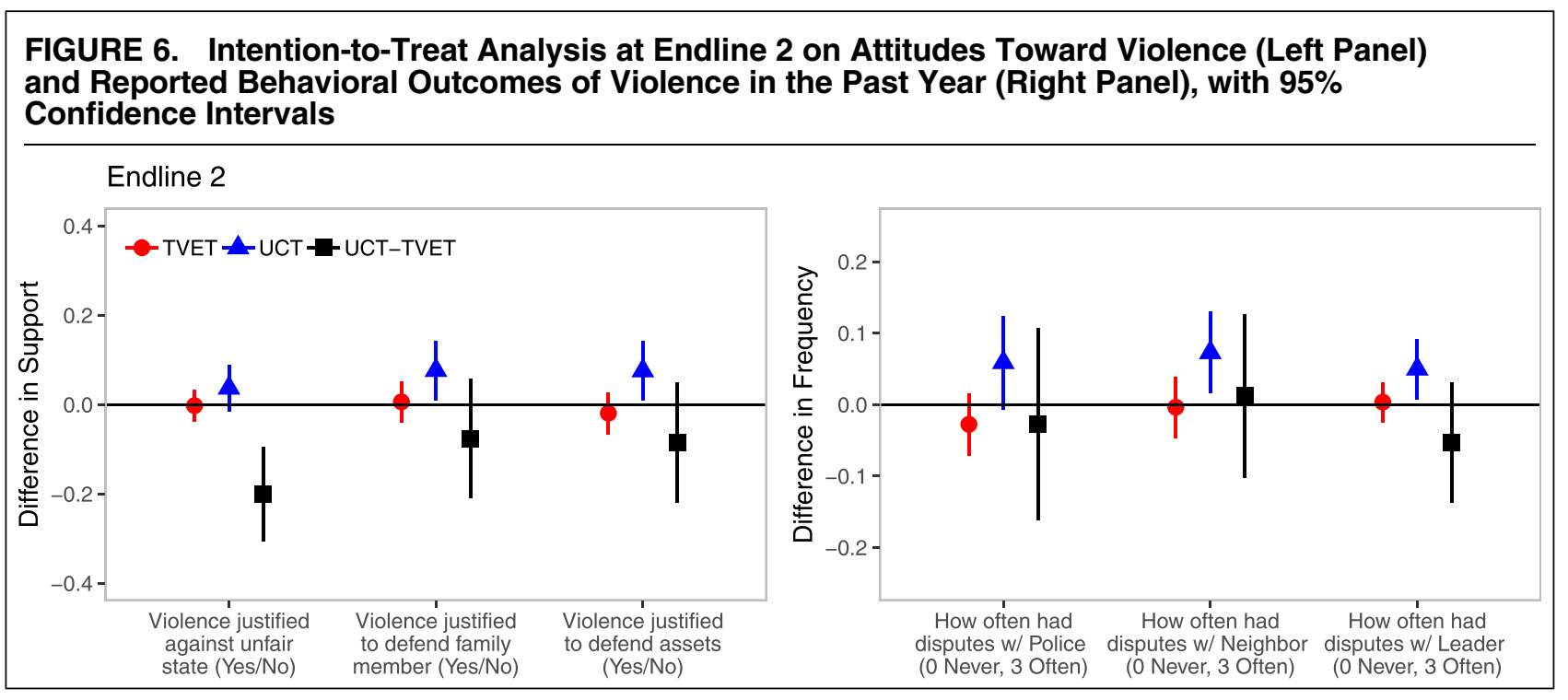

during the past year. Similarly, they reported a 3.7 percentage point difference $(95 \% \mathrm{CI}=[-1.6,9])$ when asked if "it is justified for a citizen of your country to use violence to fight against an unfair decision or law of the government." By contrast, the estimated UCT-TVET interaction effect implies a large 20 percentage point decrease in their agreement with this statement $(95 \% \mathrm{CI}$ $=[-30.6,-9.4])$.

Second, the local violence outcomes in Figure 6 are "violence justified to defend family member," "violence justified to defend assets," and "how often had disputes with a neighbor." These outcomes represent another "pull" factor that might increase an individual's support for the Taliban. Disputes with neighbors, for example, might indicate not only a greater appetite for engaging in risky acts but also creates an opening for the Taliban to attract recruits by settling local disputes in their favor. UCT recipients reported statistically significant positive effects for all three measures: a 7.7 percentage point difference in believing that violence is justified to defend family $(95 \% \mathrm{CI}=[1,14.3])$; a similar 7.6 percentage point difference in believing that violence is justified to defend assets $(95 \% \mathrm{CI}=[0.9,14.3])$; and a 0.07 difference in the frequency of having disputes with neighbors $(95 \% \mathrm{CI}=[0.02,0.13])$.

The negative consequences of the cash transfer are also apparent when we examine the UCT conditional on TVET control group. Notably, from Figure S10 of the SI, the effect on the randomized response index measure is estimated to be 10.8 percentage points $(95 \% \mathrm{CI}=$ $[1.4,20.2])$ for the UCT-TVET control group, pointing to their increased willingness to take pro-Taliban actions at Endline 2. This suggests that TVET training can reduce the upswing in pro-Taliban support created by the UCT. Additionally, Figure S11 of the SI shows the UCT-TVET control group reporting a large 14.6 percentage point increase in believing that violence is justified against an unfair state $(95 \% \mathrm{CI}=[6.9,22.3])$. In terms of local violence, these participants record a positive 11.5 percentage point increase in believing that violence is justified to defend a family member
$(95 \% \mathrm{CI}=[1.8,21.2])$, and to defend assets (12 percentage points, $95 \% \mathrm{CI}=[2.2,21.7])$. They also report having disputes with leaders more often by 7.4 percentage points $(95 \% \mathrm{CI}=[1.64,13.19])$. These findings are consistent with the claim that cash transfers generate increased resentment against the state, its agents, and even neighbors in the medium term.

\section{CREDIT CLAIMING AND THE UCT-TVET EFFECT}

Why does the UCT-TVET interaction produce such different attitudinal outcomes than either the marginal cash transfer or the vocational training effects? The political logic of signaling suggests that favorable (e.g., pro-government) shifts are most likely to occur among individuals who experience multiple interventions of varying duration and magnitude. In Kandahar, individuals have very limited exposure to government officials who often reside primarily in Kabul due to safety concerns. Poor security and few services also conspire to deepen skepticism toward both local and national politicians' ability to improve livelihoods. After a dozen years of war, attitudes are likely resistant to updating; substantial effort is thus likely needed to sway attitudes even modestly in a pro-government direction. As a result, a lone signal generated from a single economic intervention is likely to be disregarded in this environment. Two signals, however, as represented by the UCT-TVET combination, can be used to identify a pattern in government responsiveness since it provides multiple opportunities for judgment through cross-validation.

These signals are not of the same strength, however. TVET is likely a stronger indicator of government responsiveness; it involves a transfer of valued skills that hold out promise of not only immediate economic improvement but an improvement in future livelihood as well. Cash, by contrast, is a weaker signal since it provides a transitory boost to a recipient's livelihood, as 
reflected in our findings. Taken together, the two interventions allow individuals to discern a pattern in government actions, creating a trail of evidence that encourages an updating of prior beliefs. Moreover, because the two interventions are in different domains - one is a shock to future employability, the other to immediate net income - the signals they send have high discriminatory power; that is, they address different facets of livelihood and thus combine to provide more credible judgments about government capability and responsiveness than two programs that target the same economic outcome. Independent of their actual economic effects, the UCT-TVET combination generates credible evidence that the government cares about recipients' welfare and is taking steps to improve it by extracting resources from foreign donors.

Without additional surveys at shorter intervals, we cannot pin down the precise timing of when these UCTTVET interaction effects emerge. We do witness an immediate uptick, if not statistically significant, in government support at Endline 1 already. But by Endline 2, the individuals in the UCT-TVET group have already formed their new judgments about the increased efficacy of the government. Nor can we determine how long this effect might last beyond Endline 2. Still, the speed of these revised assessments of government efficacy, and in the overall shift toward government support, is noteworthy. There are strong headwinds against pro-government attitudes in Kandahar, in part because of its traditional pro-Taliban constituency and demonstrated government weakness since 2001, making this evaluation of INVEST a hard test. Given these obstacles, these results are somewhat encouraging; we may actually be underestimating the pro-government swing in support if the UCT-TVET combination was implemented in more hospitable settings.

We also note that local politicians and representatives of central agencies invested heavily in creating the public appearance that they were responsible for delivering INVEST. The program was publicly co-branded as a joint government-Mercy Corps collaboration, for example. ${ }^{27}$ All VTC training sites were located by design in government MoLSAMD facilities. Government officials attended all opening TVET sessions and frequently visited the VTCs for highly-visible "spot checks." They also contributed to the actual design of INVEST, a fact they advertised to students to indicate government concern about their welfare. Ministry officials attended graduation ceremonies, often delivering speeches before distributing government-branded certificates of completion to successful graduates (see Section S17 in the SI). Government officials also acknowledged their desire to be seen steering foreign assistance efforts. The local director of MoLSAMD, the most visible government directorate in the INVEST program, noted in an interview that government weakness meant that foreign organizations like Mercy Corps needed to "share the

\footnotetext{
${ }^{27}$ Mercy Corps nonetheless shouldered the financial burden of renting the facilities and paying salaries alone.
}

responsibility" of providing skills training. He also emphasized that NGO-government collaboration would be most effective if "NGOs share their employment programs with the government." 28

\section{DISCUSSION}

In this section, we discuss three outstanding issues: attrition, corruption, and alternative explanations for the backlash effect.

\section{Attrition}

The combination of a mobile, geographically dispersed population, unpredictable security operations, and time constraints on those searching for full-time employment also conspire to make sample attrition a possible inferential threat. We adopted several measures to reduce attrition, including frequent SMS messages to remind individuals to return for endline surveys. Nominal reimbursements of US\$5 were provided to offset the transportation costs of returning to the VTCs for each endline. Finally, we reached out through informal connections between Mercy Corps staff (including past INVEST graduates) and recent graduates to encourage them to complete the endline surveys. Of the 2,597 participants, 1,862 (71.7\%) completed Endline 1, 1,712 (65.9\%) completed Endline 2, and 1,322 (50.9\%) completed both. Table S2 in the SI provides the sample size and proportion as well as the compliance rate for each treatment group. ${ }^{29}$

While attrition clearly occurred, it is important to note that balance across remaining individuals remains high. TVET and UCT treatment status remained balanced across 20 baseline covariates between respondents at Endline 2 and those who attrited after only completing Endline 1. Using two-sided t-tests, Table S4 in Section S5 of the SI shows the assignment to TVET and/or UCT treatment did not make it more or less likely for the participant to return to Endline 2. Nevertheless, students were somewhat more likely to attrite before Endline 2 (a difference of 8.1 percentage points). So, too, were individuals with slightly greater personal assets (a difference of 0.2 on scale of 0 to 5). We ascribe the differential attrition of students to their postINVEST school schedules that made it more difficult for them to travel to the VTCs on requested days. Similarly, the slight difference in personal assets among those who attrited could be taken as signs that those individuals had higher employment, imposing time and cost constraints on returning for Endline 2. We interpret the sample at Endline 2 to be composed of the most vulnerable subset of individuals, namely, those with fewer educational opportunities and somewhat greater resource constraints. That said, the two groups remain

\footnotetext{
${ }^{28}$ MoLSAMD Director, Aino Mina VTC, Kandahar City, Kandahar, 26 December 2016.

${ }^{29}$ Since the program is a discrete, directly targeted intervention, we do not expect significant spillover effects between participants.
} 
balanced across the remaining 18 covariates with all $p$-values greater than 0.05 .

\section{Petty Corruption}

It is also possible that an alternative mechanism, petty corruption, helps explain why UCT recipients report an increase in support for the Taliban at Endline 2. If these recipients are systematically exposed to greater corruption, especially via increased contact with corrupt government officials, then it is possible that their support may shift toward the Taliban, which burnishes its image as "clean" compared with corrupt Kabul. Again, while not statistically significant, it appears UCTrecipients reported more disputes with the police - an astonishingly corrupt organization-by Endline 2 (Figure 6). We note, however, that this explanation has shortcomings. For the UCT to generate increased risk of exposure to corruption, at least one of two conditions had to hold: (1) recipient identities were known to the police; or (2) the cash induced new behaviors, including conspicuous consumption, that increased recipients' visibility to police. No evidence exists that recipient identities were compromised in any way, or even that the police were aware of INVEST. Nor did the cash transfer alter spending habits in an appreciable way; nearly all the funds were devoted to routine household consumption and rent payments. Still, we cannot definitively rule out this mechanism as an alternative explanation for the cash blowback effect.

\section{Does Non-Receipt of Cash Generate Resentment?}

We also cannot rule out completely the possibility that the non-receipt of the cash transfer made TVET trainees angry at the government, reducing the progovernment effects of TVET training. We believe that such a scenario is unlikely, however. While all participants were aware of the cash transfer, the lottery was private, with no public announcement of winners. Our SMS messages also stressed that the cash transfer was a random windfall rather than an expected outcome. Moreover, no one in our focus groups or interviews blamed the government for failure to receive cash. We do recognize the need for cash transfer programs to avoid stoking resentment and jealousy, but we do not believe such concerns are warranted here.

\section{CONCLUSION}

INVEST provided a rare opportunity to examine the effects of economic interventions on wartime political attitudes. To date, dozens of employment and training programs have been fielded in fragile states. Similarly, unconditional cash transfers have emerged as a principal tool to try to win hearts and minds. Yet our findings suggest caution. Only TVET delivered some modest economic gains that nonetheless failed to translate into either greater pro-government sentiment or reduced Taliban support. Cash transfers did temporarily increase pro-government attitudes, but these effects were short-lived and prone to backfiring especially for the UCT-TVET control group, leaving behind frustrated individuals now more pro-Taliban in outlook.

The UCT-TVET combination was more promising. Not only did these beneficiaries report increased progovernment support across multiple measures, but Taliban support also decreased modestly, despite being fielded in a Taliban-dominated area. Most surprising, these effects on combatant support occurred without economic gains, suggesting that aid may work through informational channels by creating opportunities for governments to signal their commitment to local populations. Our qualitative evidence indicates that Afghan politicians and government representatives invested heavily in publicly claiming credit for the INVEST program. The UCT-TVET package may have succeeded in nudging individuals toward a more vested stake in local political order and stability. This bottomup state-building has long been viewed as ideal by academics and policymakers but has proven elusive in top-down foreign interventions (Lake 2016).

These findings also suggest that informational dynamics in aid provision can be equally as important, if not more so, than economic motives when explaining combatant support. At least in Kandahar, combatant support proved largely resistant to material incentives, including skills provision and cash transfers. Instead, the relative success of the UCT-TVET combination hinged on the ability of local actors to claim credit for the delivery of foreign funds and services. A debate still rages over whether external funding bolsters or undermines government legitimacy; foreign funds, after all, may signal to citizens that politicians cannot provide basic goods and services. Our findings about credit capture, albeit tentative, suggest that citizens may use multiple interventions as signposts to reassess their views of government competency and responsiveness in a more favorable direction even in wartime.

Indirect methods of surveying respondents, including endorsement experiments and randomized response questions, should also move to the forefront in these investigations. Impact evaluations rely heavily on selfreports from beneficiaries who, trapped in wartime contexts, are buffeted by an array of competing pressures that can lead to severe preference falsification and strategic non-responses. Directly engaging the problem of social desirability bias will improve the quality of data while safeguarding respondents and enumerators. Our empirical strategy also advanced prior studies of combatant support by introducing disaggregated measures of action that individuals might undertake on each combatant's behalf. While behavioral measures of Taliban participation would be ideal, relevant data are difficult and risky to collect, and so these techniques may represent our best empirical strategy for linking attitudes to behavior.

While there are limitations to any single study, these findings raise policy implications for wartime economic interventions. Livelihood interventions should emphasize both skills and capital simultaneously, especially if cash constraints are severe, rather than 
implementing them as separate treatment arms (Blattman, Jamison, and Sheridan 2017). One-time cash transfers, however, should be avoided in wartime. The "boom and bust" dynamic of one-off cash shocks can stoke resentment, fueling insurgent support. Paying dividends over time might, however, prolong progovernment sentiment, increase positive examples of government credit capture, and build habits that support stability. Future studies should experiment with sequenced cash transfers of varying magnitude and conditionality. In addition, the logic of credit capture could be directly tested by randomly assigning credit for the cash transfer to NGOs, foreign donors, and different levels of the government.

More broadly, these findings underscore the need to design interventions that deliberately create opportunities for local actors to build reputations for "capturing" foreign funds. This is more than a plea for a cursory inclusion of locals. Instead, opportunities should be hardwired into these programs for local actors to design their content, play meaningful and visible roles in their implementation, and magnify their contribution publicly via outreach efforts. Program design should also reflect the possibility that interventions can have marked political effects even if they do not have economic ones. In the end, tailored, multi-pronged interventions that explicitly address the political drivers of combatant support likely offer the best means of reducing insurgent support and promoting greater stability in conflict settings.

\section{SUPPLEMENTARY MATERIAL}

To view supplementary material for this article, please visit https://doi.org/10.1017/S0003055419000698.

Replication materials can be found on Dataverse at: https://doi.org/10.7910/DVN/AQHPTT.

\section{REFERENCES}

Alfonsi, Livia, Oriana Bandiera, Vittorio Bassi, Robin Burgess, Imran Rasul, Munshi Sulaiman, and Anna Vitali. 2017. "Tackling Youth Unemployment: Evidence from a Labor Market Experiment in Uganda." STICERD-Development Economics Papers.

Amnesty International. 2016. "My Children Will Die This Winter:" Afghanistan's Broken Promise to the Displaced. Technical Report, Amnesty International.

Angrist, Joshua, Guido Imbens, and Donald Rubin. 1996. "Identification of Causal Effects Using Instrumental Variables." Journal of the American Statistical Association 91 (434): 444-55.

Attanasio, Orazio, Arlen Guarin, Carlos Medina, and Costas Meghir. 2017. "Vocational Training for Disadvantaged Youth in Colombia: A Long-Term Followup." American Economic Journal 9 (2): $131-43$.

Bastagli, Francesca, Jessica Hagen-Zanker, Luke Harman, Valentina Barca, Georgina Sturge, Tanja Schmidt, and Luca Pellerano. 2016. Cash Transfers: What Does the Evidence Say? A Rigorous Review of Programme Impact and of the Role of Design and Implementation Features. Washington, D.C.: Overseas Development Institute.

Beath, Andrew, Fotini Christia, and Ruben Enikolopov. 2011. "Winning Hearts and Minds? Evidence from a Field Experiment in Afghanistan." MIT Political Science. Working Paper No. 2011-14.

Becker, Gary. 1968. "Crime and Punishment: An Economic Approach." Journal of Political Economy 76: 169-217.
Berman, Eli, Jacob Shapiro, and Joseph Felter. 2011. "Can Hearts and Minds Be Bought? The Economics of Counterinsurgency in Iraq." Journal of Political Economy 119: 766-819.

Berman, Eli, Michael Callen, Joseph Felter, and Jacob Shapiro. 2011. "Do Working Men Rebel? Insurgency and Unemployment in Afghanistan, Iraq, and the Philippines." Journal of Conflict Resolution 55: 496-528.

Blair, Graeme, Christine Fair, Neil Malhotra, and Jacob Shapiro. 2013. "Poverty and Support for Militant Politics: Evidence from Pakistan." American Journal of Political Science 57 (1): 30-48.

Blair, Graeme, Kosuke Imai, and Jason Lyall. 2014. "Comparing and Combining List and Endorsement Experiments: Evidence from Afghanistan." American Journal of Political Science 58 (4): 1043-63.

Blair, Graeme, Kosuke Imai, and Yang-Yang Zhou. 2015. "Design and Analysis of the Randomized Response Technique." Journal of the American Statistical Association 110 (511): 1304-19.

Blair, Graeme, Yang-Yang Zhou, and Kosuke Imai. 2015. "rr: Statistical Methods for the Randomized Response." Available at the Comprehensive R Archive Network, http://CRAN.R-project.org/ package $=$ rr.

Blattman, Christopher, and Jeannie Annan. 2016. "Can Employment Reduce Lawlessness and Rebellion? A Field Experiment with High-Risk Youth in A Fragile State." American Political Science Review 110 (1): 1-17.

Blattman, Christopher, Julian Jamison, and Margaret Sheridan. 2017. "Reducing Crime and Violence: Experimental Evidence from Cognitive Behavioral Therapy in Liberia." The American Economic Review 107 (4): 1165-206.

Bullock, Will, Kosuke Imai, and Jacob Shapiro. 2011. "Statistical Analysis of Endorsement Experiments: Measuring Support for Militant Groups in Pakistan.” Political Analysis 19 (4): 363-84.

Collier, Paul, and Anke Hoeffler. 2004. "Greed and Grievance in Civil War." Oxford Economic Papers 56: 563-95.

Condra, Luke, and Jacob Shapiro. 2012. "Who Takes the Blame? The Strategic Effects of Collateral Damage." American Journal of Political Science 56 (1): 167-87.

Crost, Benjamin, Joseph Felter, and Patrick Johnston. 2014. "Aid Under Fire: Development Projects and Civil Conflict." The American Economic Review 104 (6): 1833-56.

Crost, Benjamin, Joseph Felter, and Patrick Johnston. 2016. "Conditional Cash Transfers, Civil Conflict and Insurgent Influence: Experimental Evidence from the Philippines." Journal of Development Economics 118: 171-82.

Cruz, Cesi, and Christina Schneider. 2017. "Foreign Aid and Undeserved Credit Claiming." American Journal of Political Science 61 (2): 396-408.

Dasgupta, Aditya, Kishore Gawande, and Devesh Kapur. 2017. "(When) Do Antipoverty Programs Reduce Violence? India's Rural Employment Guarantee and Maoist Conflict.” International Organization 71 (3): 605-32.

Department of the Army. 2007. U.S. Army Field Manual No. 3-24. Chicago: University of Chicago Press.

Department of the Army. 2014. Field Manual 3-24. Insurgencies and Countering Insurgencies. Headquarters, Department of the Army.

Dietrich, Simone, and Matthew Winters. 2015. "Foreign Aid and Government Legitimacy." Journal of Experimental Political Science 2 (2): 164-71.

Dietrich, Simone, Minhaj Mahmud, and Matthew Winters. 2018. "Foreign Aid, Foreign Policy, and Domestic Government Legitimacy: Experimental Evidence from Bangladesh." The Journal of Politics 80 (1): 133-48.

Evans, David, Brian Holtemeyer, and Katrina Kosec. 2018. "Cash Transfers Increase Trust in Local Government." World Bak Group Policy Research, Working Paper No. WPS 8333.

Evans, David, Brian Holtemeyer, and Katrina Kosec. 2019. "Cash Transfers Increase Trust in Local Government." World Development 114: 138-55.

Gilligan, Michael, Eric Mvukiyehe, and Cyrus Samii. 2012. "Reintegrating Rebels into Civilian Life: Quasi-Experimental Evidence from Burundi." Journal of Conflict Resolution 57 (4): 598-626.

Guiteras, Raymond, and Ahmed Mushfiq Mobarak. 2016. "Does Development Aid Undermine Political Accountability? Leader and Constituent Responses to a Large-Scale Intervention." No. w21434. National Bureau of Economic Research. 
Hirose, Kentaro, Kosuke Imai, and Jason Lyall. 2017. "Can Civilian Attitudes Predict Insurgent Violence? Ideology and Insurgent Tactical Choice in Civil War." Journal of Peace Research 54 (1): 47-63.

Hirshleifer, Sarojini, David McKenzie, Rita Almeida, and Cristobal Ridao-Cano. 2015. "The Impact of Vocational Training for the Unemployed: Experimental Evidence from Turkey." Economic Journal 126: 2115-46.

Holmer, Georgia, and Peter Bauman. 2018. Taking Stock: Analytic Tools for Understanding and Designing P/CVE Programs. Technical Report, United States Institute of Peace Washington, D.C.

Imai, Kosuke, Gary King, and Elizabeth A. Stuart. 2008. "Misunderstandings Among Experimentalists and Observationalists about Causal Inference." Journal of the Royal Statistical Society: Series A 171 (2): 481-502.

Lake, David. 2016. The Statebuilder's Dilemma: On the Limits of Foreign Intervention. Ithaca, NY: Cornell University Press.

Lee, David. 2002. "Trimming for Bounds on Treatment Effects with Missing Outcomes.” NBER Technical Working Paper No. 277.

Little, Roderick, and Donald Rubin. 2002. Statistical Analysis with Missing Data, 2nd edition. New York: Wiley.

Lyall, Jason. 2019. "Civilian Casualties, Humanitarian Aid, and Insurgent Violence in Civil Wars." International Organization 73 (4): 901-26.

Lyall, Jason, Graeme Blair, and Kosuke Imai. 2013. "Explaining Support for Combatants in Wartime: A Survey Experiment in Afghanistan." American Political Science Review 107 (4): 679-705.

Lyall, Jason, Yuki Shiraito, and Kosuke Imai. 2015. "Coethnic Bias and Wartime Informing." The Journal of Politics 77 (3): 833-48.

Manacorda, Marco, Edward Miguel, and Andrea Vigorito. 2011. "Government Transfers and Political Support." American Economic Journal: Applied Economics 3: 1-28.

McKenzie, David. 2017. "How Effective Are Active Labor Market Policies in Developing Countries? A Critical Review of Recent Evidence." The World Bank Research Observer 32 (2): 127-54.

Mikulaschek, Christoph, Saurabh Pant, and Beza Tesfaye. 2016. "Winning Hearts and Minds in Civil Wars: Governance and Support for Violence in Iraq." Unpublished Manuscript.

Nunn, Nathan, and Nancy Qian. 2014. "US Food Aid and Civil Conflict." The American Economic Review 104 (6): 1630-66.
Paler, Laura. 2013. "Keeping the Public Purse: An Experiment in Windfalls, Taxes, and the Incentives to Restrain Government." American Political Science Review 107 (4): 706-25.

Pandith, Farah. 2019. How We Win: How Cutting-Edge Entrepreneurs, Political Visionaries, Enlightened Business Leaders, and Socia Media Mavens Can Defeat the Extremist Threat. New York: Custom House.

Parkinson, Sarah. 2013. "Organizing Rebellion: Rethinking HighRisk Mobilization and Social Networks in War." American Political Science Review 107 (3): 418-32.

Popkin, Samuel.1979. The Rational Peasant: The Political Economy of Rural Society in Vietnam. Berkeley: University of California Press.

Sexton, Renard. 2016. "Aid as a Tool Against Insurgency: Evidence from Contested and Controlled Territory in Afghanistan." American Political Science Review 110 (4): 731-49.

Special Inspector General for Afghanistan Reconstruction. 2014 Lessons Learned from Oversight of the U.S. Agency for International Development's Efforts in Afghanistan. Washington, D.C.: SIGAR.

$\mathrm{Su}$, Yu-Sung, Andrew Gelman, Jennifer Hill and Masanao Yajima. 2011. "Multiple Imputation with Diagnostics (mi) in R: Opening Windows into the Black Box." Journal of Statistical Software 45: i02 Weintraub, Michael. 2016. "Do All Good Things Go Together? Development Assistance and Insurgent Violence in Civil War." The Journal of Politics 78 (4): 989-1002.

Winters, Matthew, Simone Dietrich, and Minhaj Mahmud. 2017. "Perceptions of Foreign Aid Project Quality in Bangladesh." Research and Politics 4 (4): 1-6. DOI: 2053168017735200.

World Bank. 2012. World Development Report 2011. Washington, D.C.: World Bank.

Zucco, Cesar 2013. "When Payouts Pay Off: Conditional Cash Transfers and Voting Behavior in Brazil 2002-10." American Journal of Political Science 57 (4): 810-22.

Zürcher, Christoph. 2010. Assessing the Impact of Development Cooperation in North East Afghanistan, 2005-09. Final Report Evaluation Report 049 Federal Ministry for Economic Cooperation and Development.

Zürcher, Christoph. 2017. "What Do We (Not) Know about Development Aid and Violence? A Systematic Review." World Development 98: 506-22. 